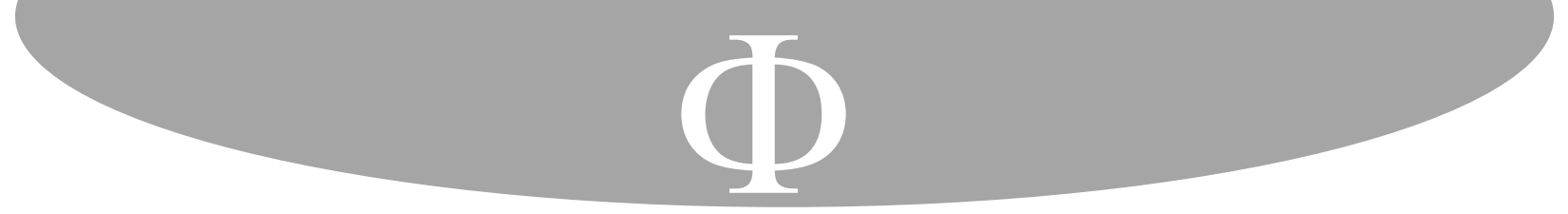

\title{
Interdisciplinariedad en el plan de estudios de la Licenciatura en Filosofía de la Universidad Pedagógica Nacional*
}

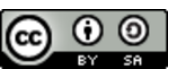

\author{
Maximiliano Prada Dussán** \\ Universidad Pedagógica Nacional \\ Bogotá D.C., Colombia
}

Para citar este artículo: Prada Dussán, Maximiliano. «Interdisciplinariedad en el plan de estudios de la Licenciatura en Filosofía de la Universidad Pedagógica Nacional». Franciscanum 175, Vol. 63 (2021): 1-27.

\section{Resumen}

El presente artículo es fruto del análisis de los planes de estudio que ha tenido la licenciatura en Filosofía de la Universidad Pedagógica Nacional desde su fundación en 2009. Al tratarse de un programa universitario que se erige en relación directa con el saber, se pregunta por los saberes que sirven de soporte a la formación de Licenciados en Filosofía. Tras este análisis, se revela que la formación de licenciados en filosofía en la UPN ha tenido dos soportes disciplinares fundamentales: la filosofía y la pedagogía. Así, el objetivo principal de este artículo es identificar y explicitar tensiones y elementos internos articuladores de los planes de estudio de la carrera con relación a estos saberes. Se muestra la función que cada uno de estos ha tenido en la configuración del plan de estudios y los modos de interdisciplinariedad que se han explorado entre ellos. El estudio describe cada uno de los soportes y sustenta que la distinción de cada uno de ellos, a la vez que los ha fortalecido independientemente, ha potenciado la interdisciplinariedad. Así, se postula que el currículo disciplinar ha sido, en este caso, la mejor estrategia para fomentar la interdisciplinariedad, en lugar de uno de carácter integrado. Como caso relevante dentro del análisis se menciona el denominado currículo alternativo o provisional, que se originó en el programa en 2017 como una apuesta de vínculo entre la formación disciplinar y la necesidad de comprender e intervenir en la coyuntura nacional.

\section{Palabras clave}

Interdisciplinariedad, Plan de estudios, Pedagogía, Filosofía, Universidad Pedagógica Nacional.

\footnotetext{
* Este artículo es producto de la investigación «Estado del arte y balance del conocimiento construido en la Licenciatura en Filosofía de la Universidad Pedagógica Nacional en el período 2009-2018», código DCS 50719, financiada por la subdirección de gestión de proyectos CIUP, en la vigencia 2019, en la Universidad Pedagógica Nacional. Agradezco a los miembros del equipo de investigación sus aportes en la consolidación de esta idea y, especialmente, a Karol Nossa por su ayuda y lectura detenida.

** Doctor en Filosofía por la Universidad Complutense de Madrid. Profesor de la Licenciatura en Filosofía de la Universidad Pedagógica Nacional. Coordinador del proyecto de investigación. Contacto: aprada@pedagogica.edu.co. ORCID: https://orcid.org/0000-0003-0204-8801.
} 


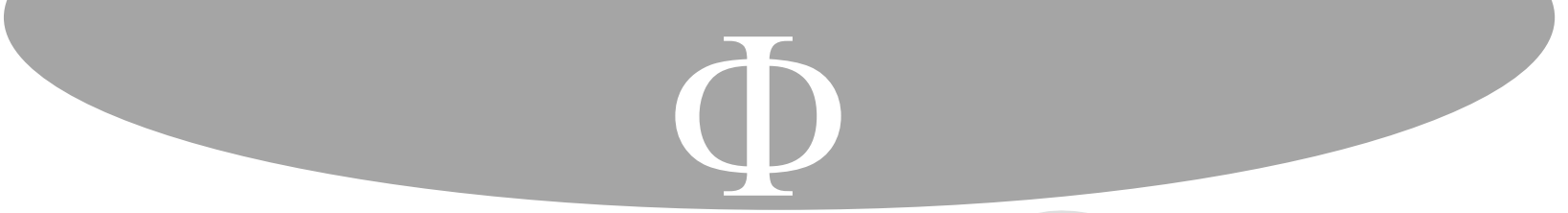

corrientes de las disciplinas académicas, de las necesidades de formación que han fijados los entes gubernamentales y las instituciones, de los adelantos de las tecnologías, de las posibilidades previstas de desempeño profesional de los egresados e, incluso, de la formación y perfiles de personas y grupos involucrados en el diseño del plan. ${ }^{9}$ Pinar, a este respecto, señala que la selección tiene también un sentido histórico, pues en él «decidimos qué recordar del pasado, qué creer del presente y qué esperar y temer del futuro» ${ }^{10}$.

La idea según la cual el plan de estudios es una selección ha sido puesta de presente fundamentalmente en los estudios sobre el currículo escolar; en el campo específico de la filosofía, a su vez, recientemente nos hemos aproximado en nuestro país a esta noción, sentando las bases para comprender la filosofía como disciplina escolar ${ }^{11}$. Asimismo, ha habido aproximaciones para analizar el plan de estudios universitario, especialmente en los ejercicios de reconstrucción histórica de los programas y facultades de filosofía del país, poniendo de presente las elecciones formativas que las instituciones han tomado. Es este nuestro caso, como veremos a lo largo de este escrito.

En cuanto selección, se toman elementos de aquí y allá, pero, además de ello, se da el fenómeno que Simons y Masschelein denominan profanación ${ }^{12}$ : esto es, otorgar un nuevo sentido a los contenidos, destrezas o elementos que se toman. La profanación, tal como los autores la emplean, no se inscribe en un sentido religioso o sagrado. En lugar de ello, quieren señalar que en la escuela los elementos, contenidos o ideas elaboradas por la sociedad, en sus comunidades académicas, de investigación o culturales, son despojados o suspendidos del sentido que se les había otorgado en los contextos en que emergieron y se les da un sentido relacionado con la formación. Es un sentido contextualizado. De allí que la selección, en

referentes fundamentales que estructuran un plan de estudios son la tradición científica o académica, la tradición utilitaria o laboral y la tradición pedagógica. Para ver cómo estos elementos configuraron la disciplina escolar de la filosofía en Colombia en el siglo XX, ver: Víctor Montes y Julián Montes, La filosofía como disciplina escolar en Colombia 1946-1994 (Bogotá: Aula de Humanidades, 2019), 40ss.

${ }^{9}$ La tradición filosófica y pedagógica revela, de una u otra forma, que la formación no se restringe a la trasmisión de contenidos sin que medie una selección de los mismos, por parte de las personas encargadas de definirlo. Citamos algunos casos conocidos en estas tradiciones: recuérdese, por un lado, el rechazo de Platón hacia los artistas, en los libros III y X de la República, por motivos pedagógicos. Agustín, en De Ordine, libro II, define el marco de las Artes liberales, con lo cual traza una distinción entre estas y las artes útiles, que quedan desechadas de la educación que conduce a la liberación del alma. Comenio, por su parte, en el capítulo XXV de la Didáctica Magna desecha los libros de los gentiles como referentes para que el estudiante alcance la verdad.

${ }^{10}$ William Pinar, La teoría del Currículum, 70. Pinar se refiere tanto al currículo en sentido amplio como al plan de estudios, en particular.

${ }^{11}$ En Colombia, recientemente nos hemos aproximado a esta noción y a las cuestiones que a ella subyacen. Véase al respecto los siguientes trabajos. Germán Vargas y Luz Gloria Cárdenas, Filosofía, Pedagogía y Enseñanza de la Filosofía (Bogotá: Universidad Pedagógica Nacional, 2004). Óscar Saldarriaga, «De universidades a colegios: la filosofía escolar y la conformación del bachillerato moderno en Colombia, 17921892», en Genealogías de la colombianidad. Formaciones discursivas y tecnológicas de gobiernos en los siglos XIX y XX (Bogotá: Instituto Pensar-Pontificia Universidad Javeriana, 2008). Víctor Montes y Julián Montes, La filosofía como disciplina escolar en Colombia 1946-1994.

${ }^{12}$ Maarten Simons y Jan Masschelein, Defensa de la escuela: una cuestión pública (Buenos Aires: Miño y Dávila, 2014), 40. 


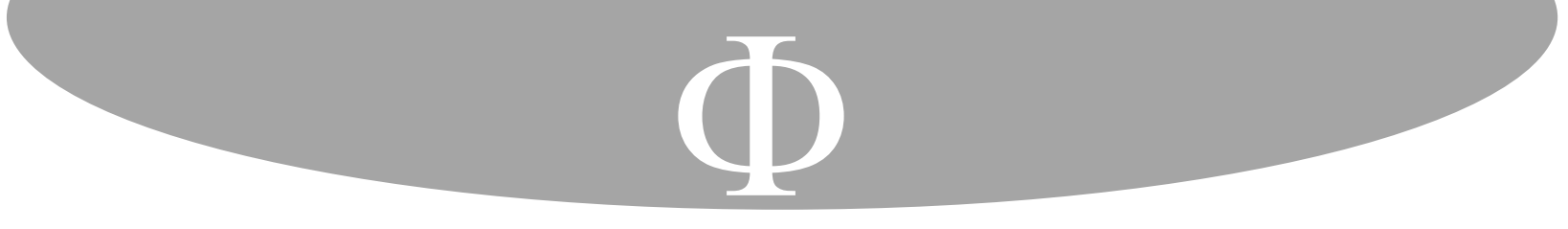

sentido amplio, conlleve, en su seno, también un acto de apropiación por parte de las comunidades que les otorgan nuevo sentido. Es un concepto a través del cual se señala que la escuela y universidad son lugares de construcción activa de sentido, más que de recepción de sentidos provenientes de su exterior; sin que ello implique que se renuncia a la comunicación entre las instituciones y el conjunto de la sociedad.

Como diversas corrientes de investigación educativa lo han mostrado, la selección no es neutra ${ }^{13}$ lo cual no implica que se trate de una selección arbitraria. En la selección se sopesan elementos, se define cuáles de ellos se consideran más pertinentes, potentes o importantes para los propósitos generales de formación, de modo que se proponen como elementos que estructuran y tensionan el plan de estudios, por encima de otros que también pueden estar presentes, pero que no se consideran constituyentes. Se construyen nuevos contenidos, se entrelazan unos y otros y se otorgan nuevos sentidos a lo seleccionado, como acto de apropiación. De allí que la selección, por otra parte, dé como resultado un producto diferenciado, un tipo de objeto que, como todo objeto de investigación ${ }^{14}$, funge como receptáculo de proposiciones, por lo cual puede ser tematizado para su estudio.

En cuanto objeto, por otra parte, tiene la posibilidad de ser único, diferenciado, original. Esto no obsta para que los planes de estudio de distintas regiones o instituciones tengan un aire de familia o tengan elementos comunes, pues muchos de los referentes que mencionamos son comunes a las instituciones. Sin embargo, la autonomía con que cuentan las comunidades que los diseñan (bien sea que esta se sitúe en entes gubernamentales o se sitúe en las instituciones, como es nuestro caso), que les permite tener un margen de decisión sobre estos asuntos, y el interés que se tiene de que los planes de estudios respondan pertinentemente a los diversos contextos con los que se relaciona, hace que tenga la posibilidad de ser original, diferenciada.

La distinción entre currículo y plan de estudios es útil para nuestros propósitos, porque delimita el tipo de objetos que analizaremos en este texto: el plan de estudios representa esquemáticamente el conjunto de las materias o espacios académicos ${ }^{15} \operatorname{con} \mathrm{su}$ distribución horaria, número de créditos y criterios de distribución. Al centrar la mirada en el plan de estudios se pone en primer plano la apuesta formativa con relación a la explicitación del saber implicado, entre otros aspectos que podrían ser analizados en el sentido amplio de currículo. En efecto, obliga a considerar el contenido, sentido y carácter del área de formación, la filosofía, tanto como su enlace con la pedagogía, en cuanto esta última configura un conjunto de materias, pero, a la vez, introduce criterios relevantes para

\footnotetext{
${ }^{13}$ José Gimeno Sacristán, ¿Qué significa el currículum? Sus determinaciones visibles e invisibles. William Pinar, La teoría del currículo. En especial la pedagogía crítica ha puesto de relieve las relaciones entre el orden político y económico establecido con el currículo escolar. Ver Michael Apple, Ideología y currículo (Madrid: Akal, 1991).

14 Germán Vargas, Investigaciones epistemológicas (Rionegro: Fundación Universitaria del Oriente Antioqueño-Tecné, s. f), 33.

${ }^{15}$ En la UPN, las licenciaturas se denominan proyectos curriculares. Las materias o asignaturas, a su turno, se denominan espacios académicos.
} 


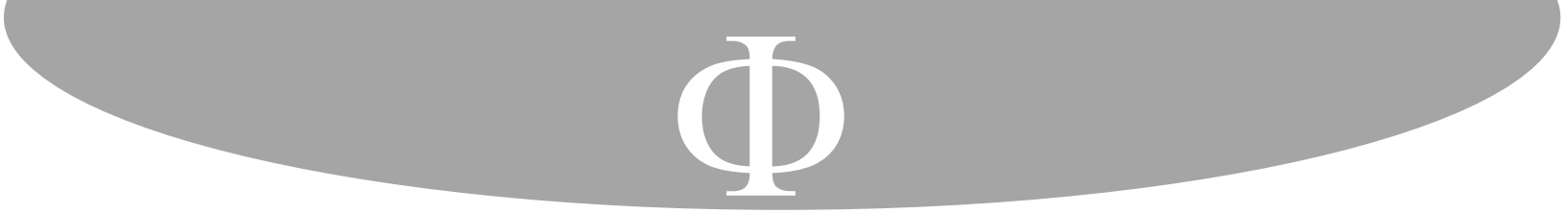

No hubo consenso sobre cómo denominar este otro currículo, ${ }^{74}$ pero su sentido se puede extraer de las etiquetas señaladas. Por «alternativo» se comprendió un currículo distinto al formal, al aprobado por las instancias universitarias y el Ministerio de Educación Nacional. Alternativo, también, hace alusión a que dicha palabra se usa para señalar que con ella se recoge lo que no está explícito, lo oculto. Se trata de la emergencia de otra tradición de pensamiento; estudiantes y profesores que, en este caso, exigen pensar directamente las realidades políticas del país. Es pensar tanto la filosofía, como los asuntos políticos del país, de otra manera. Se trata de un modo de explicitación del currículo oculto. La etiqueta «provisional», por su parte, se refiere a que no se pretende que dicha situación se prolongue en el tiempo; no se espera que se perpetúe o se estabilice. Es el modo en que se puede continuar estudiando, persiguiendo los objetivos de formación y atendiendo las necesidades del país, en medio de la coyuntura del paro y el cierre de los salones.

La experiencia del currículo alternativo o provisional tuvo otros aspectos que merecen ser relevados. Por un lado, la amplia participación de profesores y estudiantes. La posibilidad misma de emprender esta forma de currículo tuvo como condición el acuerdo del conjunto de la Licenciatura. Estudiantes y profesores defendieron la propuesta, incluso, al punto de exponerla y hacerla valer mientras en los demás programas de la universidad no era posible continuar con los estudios. Se trata, pues, de una experiencia cuyo valor está también en la construcción colectiva. Constituye, además, un eslabón para que en años posteriores se postulara la horizontalidad en el programa, como modelo de gestión y principio de construcción de conocimiento en la carrera.

El segundo elemento para destacar es que implicó un aumento significativo de actividades y, por ende, un esfuerzo extra de todos para el desarrollo de las actividades. No se trató de una experiencia en la que se experimentara una relajación de esfuerzos. Por el contrario, implicó más trabajo, pues había que replantear contenidos, diseñar actividades, llegar a acuerdos, preparar nuevos materiales, etc. Las evaluaciones posteriores que realizó la Licenciatura sobre tal experiencia señalaron de modo especial el agotamiento al que estas iniciativas conducen, de modo tal que, aunque ha habido nuevas situaciones de bloqueos de edificios, no se ha vuelto a plantear la alternativa de modificar el currículo. Ello resaltó su carácter de provisionalidad.

Aun así, el currículo alternativo o provisional lanzó preguntas relevantes al programa: ¿nuestra formación nos prepara para afrontar las cuestiones acuciantes de la realidad nacional? ¿Es posible otro modo y otros contenidos del filosofar? ¿La filosofía que practicamos da la cara al país? Estas y otras preguntas que emergieron de tal experiencia están a la espera de ser tratadas. Quizás en la siguiente reforma del plan de estudios.

\footnotetext{
${ }^{74}$ Como se puede notar, además, se le dio la denominación de currículo y no de plan de estudios, debido a que se postuló transformar no solo el contenido y organización de las materias, sino las metodologías, didácticas, experiencias formativas, entornos e, incluso, modos de evaluación. Insistimos en que lo aquí señalado de tal experiencia no agota lo allí acontecido. Es solo una aproximación coherente con la aproximación teórica que realizamos en el conjunto de este texto.
} 
